\title{
The Bacillus subtilis yabQ gene is essential for formation of the spore cortex
}

\author{
Kei Asai, ${ }^{1}+$ Hiromu Takamatsu, ${ }^{2}$ Megumi Iwano, ${ }^{1}$ Takeko Kodama, ${ }^{2}$ \\ Kazuhito Watabe ${ }^{2}$ and Naotake Ogasawara ${ }^{1}$
}

Author for correspondence: Naotake Ogasawara. Tel: +81 74372 5430. Fax: +81743 725439.

e-mail:nogasawa@bs.aist-nara.ac.jp

\footnotetext{
1 Department of Cell Biology, Graduate School of Biological Sciences, Nara Institute of Science and Technology, 8916-5, Takayama, Ikoma, Nara 630-0101, Japan

2 Faculty of Pharmaceutical Sciences, Setsunan University, 45-1, Nagaotoge, Hirakata, Osaka 573-0101, Japan
}

\begin{abstract}
An extensive screening for transcripts with probes specific for the genes in a $108 \mathrm{~kb}$ region from rrnO to spoOH of the Bacillus subtilis chromosome led to identification of an operon, yabP-yabQ-divIC-yabR, the expression of which was initiated at the second hour of sporulation and in a $\sigma^{\mathrm{E}}$-dependent manner. Among three $y$ genes in the operon, deletion of the yabQ gene, which is predicted to encode a protein product of 468 residues with five membranespanning domains, resulted in a large decrease in numbers of chloroform-, lysozyme- and heat-resistant spores, compared to findings with the wild-type strain. Electron microscopy revealed that development of the spore cortex was blocked in the yabQ mutant. In addition, although the spore coat was visible, the inner coat layer of the mutant seemed partially detached from the outer coat. In sporangia of the strains harbouring an in-frame fusion of the green fluorescent protein gene to $y a b Q$, fluorescence was detected around the forespore. This localization did not depend on SpolVA or on CotE functions, both of which determine proper localization of coat proteins and cortex formation. The yabQ deletion did not affect expression of genes involved in cortex synthesis. These results suggest that the YabQ protein localizes in the membrane of the forespore and plays an important role in cortex formation.
\end{abstract}

Keywords: Gram-positive bacterium, sporulation, cell differentiation, green fluorescent protein

\section{INTRODUCTION}

The Gram-positive soil bacterium Bacillus subtilis produces dormant spores which can survive for long periods and under extreme conditions when environmental nutrition is exhausted (reviewed by Piggot \& Coote, 1976; Losick et al., 1986; Errington, 1993). B. subtilis initiates spore formation by dividing asymmetrically, the result being formation of a larger mother cell and a smaller forespore cell. The mother cell engulfs the forespore so that it is surrounded by a double membrane. Peptidoglycan accumulates in the inter-space of the two membranes and forms a thick spore cortex that provides resistance against heat and organic solvents. In addition, the proteinaceous spore coat is layered on the outer

\footnotetext{
†Present address: Department of Biochemistry and Molecular Biology, Faculty of Science, Saitama University, 255 Shimo-Ohkubo, Urawa, Saitama 338-8570, Japan.

Abbreviation: GFP, green fluorescent protein.
}

surface of the forespore double membrane and protects the spore from actions of all large molecules, including lytic enzymes such as lysozyme. More than 100 genes involved in these developmental stages have been identified and their biological functions analysed. RNA polymerases containing developmentally specific sigma factors, $\mathrm{E} \sigma^{\mathrm{H}}, \mathrm{E} \sigma^{\mathrm{F}}, \mathrm{E} \sigma^{\mathrm{E}}, \mathrm{E} \sigma^{\mathrm{G}}$ and $\mathrm{E} \sigma^{\mathrm{K}}$, temporally and spatially activated during sporulation, regulate expression of the sporulation genes in a stage-specific and compartment-specific manner (Igo \& Losick, 1986; Stragier et al., 1988; Stragier \& Losick, 1996).

With completion of the sequencing of the B. subtilis genome, we might be able to identify all the genes involved in the sporulation process described above. In a $108 \mathrm{~kb}$ segment of the $B$. subtilis genome that covers between $\mathrm{rrnO}$ and $s p o 0 \mathrm{H}, 90$ ORFs were found, 52 of which had unknown function (Ogasawara et al., 1994). To identify novel genes involved in sporulation, Northern analysis was done using probes encompassing each gene in this region. We searched for genes that were transcribed after the onset of sporulation and whose 
inactivation caused some effects on spore formation and germination. We characterized two genes, yaaH and yabG, which were specifically induced during sporulation and involved in germination of spores and assembly of the spore coat, respectively (Kodama et al., 1999; Takamatsu et al., 2000). We now report the function of the $y a b Q$ gene expressed during sporulation by $\mathrm{E} \sigma^{\mathrm{E}}$ and which is involved in formation of the spore cortex.

\section{METHODS}

Bacterial strains and plasmids. B. subtilis strains and plasmids used in this study are listed in Table 1.

An in-frame deletion mutation of $y a b P$ or $y a b Q$ was obtained by two-step allele replacement, as described by Asai et al. (2000). Genomic regions upstream and downstream of yabP were PCR-amplified using a primer pair of bPUF $\left(5^{\prime}-\right.$ GGTTTCTGAAGCTCCTCACG-3') and bPUR (5'-CCCTTTAGCTTTATCCCCATTCATCTATTCAGCCCCC-3'), and a primer pair of bPDF (5'-GGGGGCTGAATAGATGAATGGGGATAAAGCTAAAGGG-3') and bPDR (5'-CCGTGTGATGGTCGTTCT-3'), respectively, then used to obtain a B. subtilis strain, ASK220, in which codons 3-87 of the yabP structural gene (100 aa) were deleted. Genomic regions upstream and downstream of $y a b Q$ were PCR-amplified using a primer pair of bQUF (5'-GCGAAGGAAGTAGCTGACC$\left.3^{\prime}\right)$ and bQUR (5'-GGAGAAAACCTATCAGGCTCAGCGTCATTTAAACAACTTGC-3'), and a primer pair of bQDF (5'-GCAAGTTGTTTAAATGACGCTGAGCCTGATAGGTTTTCTCC-3') and bQDR (5'-TACTTGCTCTTCTTCTCCAC- $\left.3^{\prime}\right)$, respectively, then used to obtain a $B$. subtilis strain, ASK221, in which codons 4-140 of the yabQ structural gene (211 aa) were deleted.

Oligonucleotide primers 8158RTF (5'-CGGCCAAAAGCTTGTAAC- $\left.3^{\prime}\right)$ and 8158RTR (5'-GGAGGATCCATAATATGAATTCATCTATTCAG-3') were used to amplify a $208 \mathrm{bp}$ segment of the yabP upstream region. The PCR product, restricted at HindIII and BamHI sites introduced by the primers, was inserted into the HindIII/BamHI-restricted pMUTINT3 (Vagner et al., 1998; Moriya et al., 1998) to obtain plasmid pMU158RT. The resulting plasmid was transformed into $B$. subtilis 168 by a single cross-over recombination for erythromycin resistance $(0.5 \mu \mathrm{g}$ erythromycin $\mathrm{ml}^{-1}$ ), to yield strain ASK222.

An integration vector for green fluorescent protein (GFP) fusion was constructed as follows. A fragment encoding the Cterminal portion of $\mathrm{YabQ}$ and a fragment encoding the Cterminal portion of CotE were PCR-amplified using primers QGFPF (5'-GTCGTCGACATGCGGAGCGATCATC-3') and QGFPR (5'-GAAGAATTCTCTCTTCAAAAACCGTGTG-3'), and COTEGFPF (5'-GTCGTCGACCATTTCGCCGAATGG-3') and COTEGFPR (5'-GAAGAATTCTTCAGGATCTCCCAC-3'), respectively. The PCR products of 280 and $208 \mathrm{bp}$ were digested by SalI and EcoRI and introduced between the SalI and EcoRI sites of pMm2 (Takamatsu et al., 2000) to generate plasmids pMmyabq and pMmcote, respectively. The resultant plasmids were transformed into B. subtilis 168 by a single cross-over for erythromycin resistance to yield strain ASK223 or ASK226 in which the $y a b Q$ or $\cot E$ genes were switched with the $y a b Q-$ or $\cot E-g f p$ genes, respectively. The $y a b Q-g f p$ fusion was transferred to the chromosome of B. subtilis P20 (Coot, 1972) and B. subtilis RL48 (Zheng et al., 1988) and the resulting strains were named ASK224 and ASK225, respectively. The

Table 1. B. subtilis strains and plasmids used in this study

\begin{tabular}{|c|c|c|}
\hline Strain or plasmid & Genotype or description & Source or reference \\
\hline \multicolumn{3}{|l|}{ Strains } \\
\hline 168 & $\operatorname{trp} C 2$ & Laboratory stock \\
\hline ASK203 & $\operatorname{trp} C 2$ spollGAB::kan & Kodama et al. (1999) \\
\hline ASK204 & $\operatorname{trpC2}$ spollIG::kan & Kodama et al. (1999) \\
\hline ASK205 & $\operatorname{trp} C 2$ spolVCB::erm & Kodama et al. (1999) \\
\hline ASK220 & $\operatorname{trp} C 2$ yabP $\Delta 1$ & This work \\
\hline ASK221 & $\operatorname{trp} C 2$ yabQ $\Delta 1$ & This work \\
\hline ASK222 & 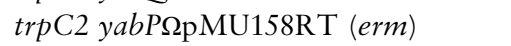 & This work \\
\hline ASK223 & $\operatorname{trp} C 2$ yabQ-gfp (erm) & This work \\
\hline P20 & pheA12 spoIVA178 & Coot (1972) \\
\hline RL48 & $\operatorname{trp} C 2 \cot E:$ :cat & Zheng et al. (1988) \\
\hline ASK224 & pheA12 yabQ-gfp (erm) spoIVA178 & This work \\
\hline ASK 225 & $\operatorname{trp} C 2$ yabQ-gfp (erm) $\cot E:: c a t$ & This work \\
\hline ASK226 & $\operatorname{trp} C 2 \cot E-g f p(\mathrm{erm})$ & This work \\
\hline KP429 & $a m y E:: g f p-s p o I V A$ & Price \& Losick (1999) \\
\hline ASK227 & 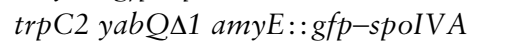 & This work \\
\hline ASK228 & $\operatorname{trp} C 2$ yabQ $\Delta 1 \cot E-g f p(\mathrm{erm})$ & This work \\
\hline \multicolumn{3}{|l|}{ Plasmids } \\
\hline pMUTINT3 & erm bla lacZ lacI Pspac & $\begin{array}{l}\text { Vagner et al. (1998); } \\
\text { Moriya et al. (1998) }\end{array}$ \\
\hline pMU158RT & erm bla yabP'-'lacZ lacI Pspac-'yabP & This work \\
\hline pMm2 & erm bla gfp lacI Pspac & Takamatsu et al. (2000) \\
\hline pMmyabq & erm bla yabQ-gfp lacI Pspac-'yabQ & This work \\
\hline pMmcote & erm bla cotE-gfp lacI Pspac-'cotE & This work \\
\hline
\end{tabular}


(a)

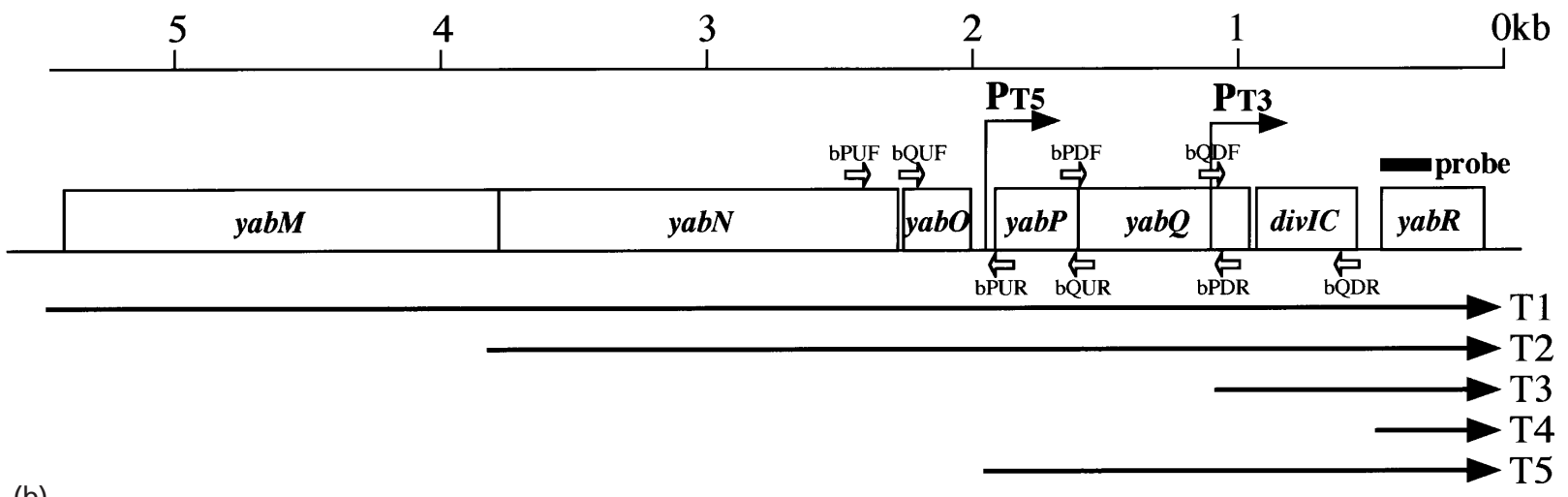

(b)

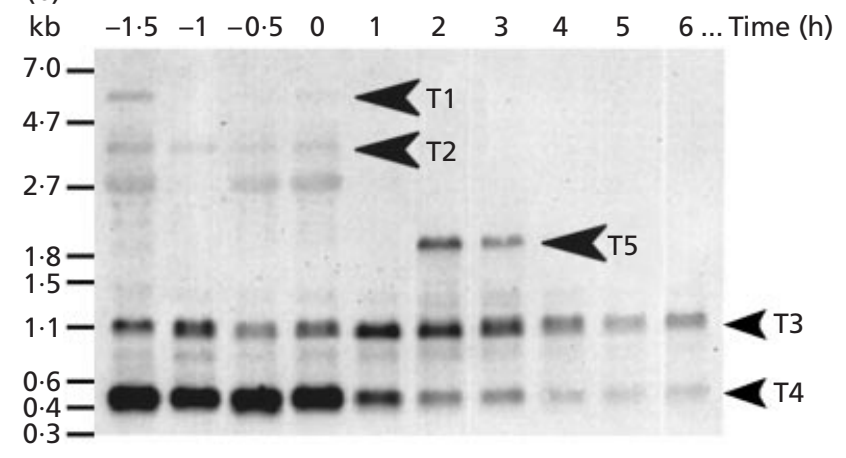

(c)

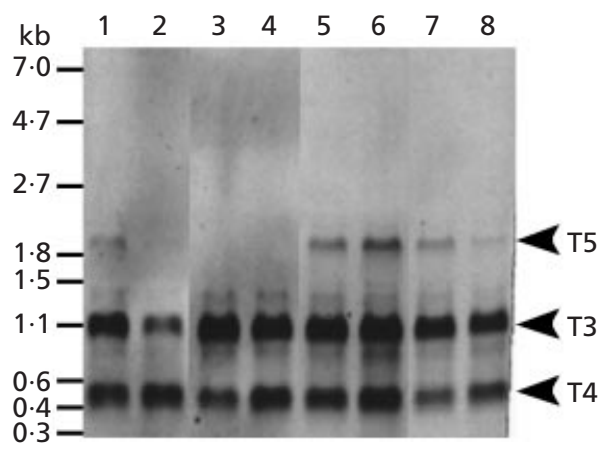

Fig. 1. (a) Arrangement of genes around the yabQ locus on the $B$. subtilis genome. Transcripts detected by a probe encompassing the 5'-portion of yabR (indicated by a thick bar) are shown by arrows below the ORF map, and are designated T1, T2, T3, T4 and T5, respectively. The genes covered by these transcripts were determined by Northern analysis experiments using probes covering each gene indicated in the figure. The positions of the $E \sigma^{\mathrm{E}}$-dependent promoter $\left(\mathrm{P}_{\mathrm{TS}}\right)$ and promoter for the divIC-yabR genes $\left(\mathrm{P}_{\mathrm{T} 3}\right)$ are also shown on the map. The primer-binding sites used for two-step deletion mutants are indicated by open arrows. (b) Northern blot using the yabR specific probe. Total RNA was prepared from a B. subtilis 168 culture in DS medium at the times shown on the top of the blot (hours before and after the end of the vegetative growth phase). The approximate positions of transcripts are indicated. The size of RNA is shown on the left of the blot. (c) Northern blots using RNA from the wild-type (lanes 1 and 2), spollGAB (lanes 3 and 4), spollIG (lanes 5 and 6) or spoIVCB (lanes 7 and 8) mutants and the yabR specific probe. Total RNA was prepared from the cells at $2 \mathrm{~h}$ (lanes 1, 3, 5 and 7) and $4 \mathrm{~h}$ (lanes 2, 4, 6 and 8) after the end of vegetative growth. The approximate positions of transcripts and the size of RNA are shown as in (b).

gfp-spoIVA (Price \& Losick, 1999) and cotE-gfp fusions were transferred to the chromosome of ASK221 and the resulting strains were named ASK227 and ASK228, respectively. Transformation of $B$. subtilis was done as described by Kawamura et al. (1980).

Sporulation medium and measurement of spore resistance. Difco sporulation (DS) medium (Schaeffer et al., 1965) was used to produce $B$. subtilis spores. Cells were grown in DS medium at $37^{\circ} \mathrm{C}$ for $18 \mathrm{~h}$ after the end of exponential growth, and the spore resistance was assayed as follows. The culture was heated at $80^{\circ} \mathrm{C}$ for $30 \mathrm{~min}$, and treated with lysozyme (final concentration, $0.25 \mathrm{mg}$ lysozyme $\mathrm{ml}^{-1}$ ) at $37^{\circ} \mathrm{C}$ for $10 \mathrm{~min}$, or with $10 \%(\mathrm{v} / \mathrm{v})$ chloroform at room temperature for $10 \mathrm{~min}$, as described by Nicholson \& Setlow (1990). A portion of the sample was diluted in distilled water, plated on Luria-Bertani agar, and incubated overnight at $37^{\circ} \mathrm{C}$. The number of survivors was determined by counting colonies.

Northern and primer extension analysis. Total RNA was extracted from B. subtilis cells as described by Igo \& Losick (1986). In Northern analysis, hybridization and detection were performed using digoxigenin-labelled RNA probes (Asai et al., 2000). Primer extension analysis was carried out using digoxigenin-end-labelled primers (Takamatsu et al., 2000).
DNA ladders for size markers were obtained using the same digoxigenin-end-labelled primers and a DIG Taq DNA sequencing kit (Boehringer Mannheim).

Phase-contrast and fluorescence microscopy. An aliquot of the culture of B. subtilis cells in DS medium was transferred onto a microscope slide coated with poly-L-lysine. Images of phase-contrast and fluorescence from GFP were observed under an Olympus fluorescence microscope (AX70) with a UMNIBA mirror cube unit. The images were captured with a cooled charge-coupled device camera (PXL-1400; Photometrics) and analysed using image processing software, IPLAB spectrum (Signal Analytic Corporation).

Electron microscopy. Glutaraldehyde was added to a final concentration of $0.3 \%(\mathrm{w} / \mathrm{v})$ to the culture of $B$. subtilis cells allowed to sporulate for 8,10 and $18 \mathrm{~h}$ after the onset of sporulation. The cells were collected by centrifugation and prefixed with $3 \%(\mathrm{w} / \mathrm{v})$ glutaraldehyde in $50 \mathrm{mM}$ phosphate buffer ( $\mathrm{pH}$ 6.5) for $2 \mathrm{~h}$ at room temperature, followed by washing five times with the same buffer. Cells were then collected by centrifugation and fixed with a final concentration of $1 \%(\mathrm{w} / \mathrm{v})$ osmium tetroxide in $50 \mathrm{mM}$ phosphate buffer ( $\mathrm{pH}$ 6.5) for $2 \mathrm{~h}$ at room temperature. After washing five times with distilled water, they were prestained for $2 \mathrm{~h}$ with $0.5 \%$ 
$(\mathrm{w} / \mathrm{v})$ uranyl acetate and embedded in $2 \%(\mathrm{w} / \mathrm{v})$ agar. The agar block was dehydrated with ethanol and acetone, followed by embedding in Spurr's resin (Spurr, 1969) prior to thin sectioning. Thin sections were obtained using a Diatome diamond knife on a Leica ULTRACUT UCT, stained with $3 \%(\mathrm{w} / \mathrm{v})$ uranyl acetate and then with lead citrate (Reynolds, 1963), and examined under a Hitachi H7100 electron microscope.

\section{RESULTS AND DISCUSSION}

An operon containing the yabP, yabQ, divIC and $y a b R$ genes is induced at the middle stage of sporulation by RNA polymerase containing $\sigma^{\mathrm{E}}$

Through systematic Northern analysis of transcripts in a chromosomal region between $r r n \mathrm{O}$ and $s p o O H$, a 1.9 $\mathrm{kb}$ transcript which appeared $2 \mathrm{~h}$ after the onset of sporulation was detected using a probe specific for the yabR gene (Fig. 1b). This transcript also hybridized with probes specific for the yabP, yabQ and divIC genes (data not shown). The size of the transcript corresponded exactly to the nucleotide length covering the start of $y a b P$ to the end of $y a b R$, indicating that the four genes were co-transcribed at the middle stage of sporulation (T5 in Fig. 1a). To determine which sigma factor was concerned with the transcription, Northern analysis was done using RNA prepared from sigma-factor-deficient mutants. The results in Fig. 1(c) show that while the transcript was detected in spoIIIG $\left(\sigma^{\mathrm{G}}\right)$ and spoIVCB $\left(\sigma^{\mathrm{K}}\right)$ mutants, it disappeared in the spoIIGAB $\left(\sigma^{\mathrm{E}}\right)$ mutant. In addition, we determined the $5^{\prime}$-terminus of the transcript in a primer extension experiment and found possible -10 and -35 sequences of the $\mathrm{E} \sigma^{\mathrm{E}}$ promoter (Fig. 2). (a)

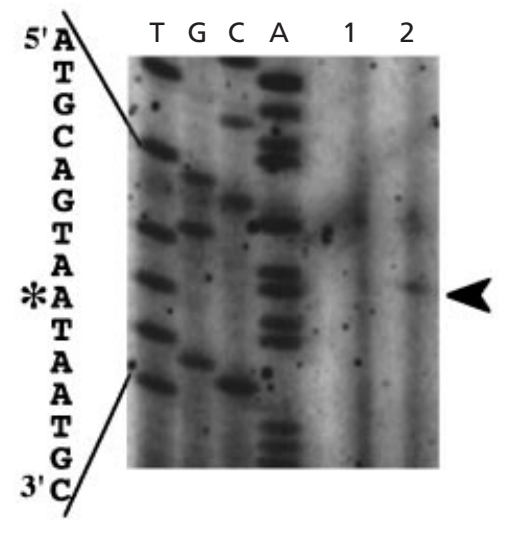

(b)

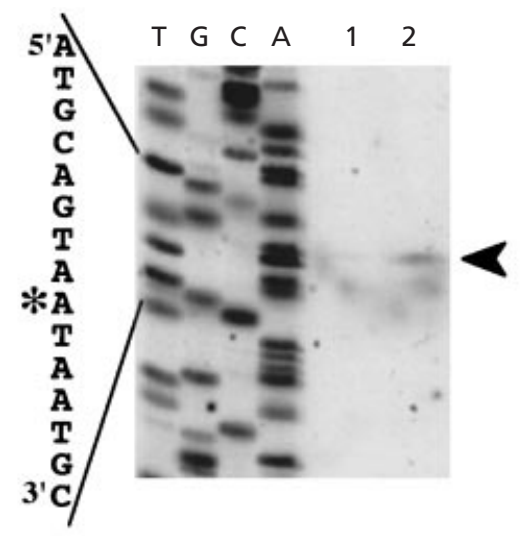

(c)

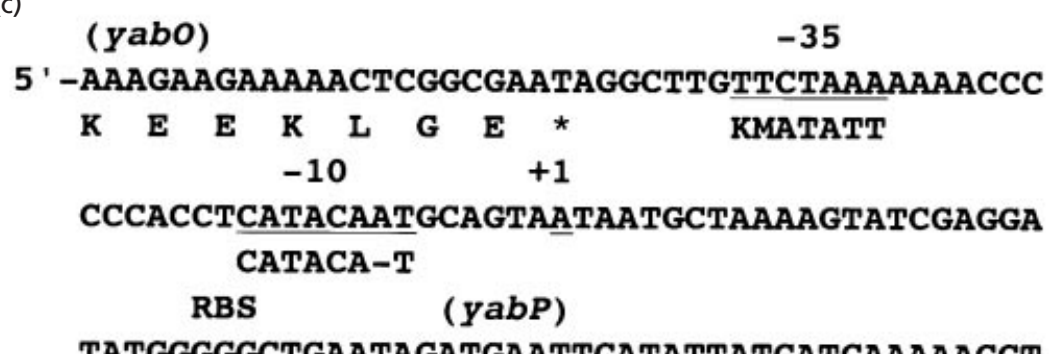

TATGGGGGCTGATAGATGAATTCATATTATGATCAAAAAGGT-

$$
\begin{array}{lllllllll}
M & \text { N } & \text { S } & \text { Y } & \text { Y } & \text { D } & \mathbf{Q} & \text { K } & \text { G }
\end{array}
$$

Fig. 2. Determination of the start site of the T5 transcript by primer extension. Total RNA was prepared from strain ASK222 at the end of the vegetative phase of growth (lane 1) and $2 \mathrm{~h}$ later (lane 2), and primer extension experiments were done, as described in Methods, using primers RT1 (a) or RT2 (b). Sequencing ladders were generated using the primers used for the reverse transcriptase reaction (lanes labelled by $T, G$, C and A). The extension product is marked with an arrowhead. The sequence and the transcription start sites (indicated by asterisks) are shown. (c) Nucleotide sequence of the promoter region of the T5 transcript. The deduced amino acid sequences of the C-terminal portion of YabO and the $\mathrm{N}$-terminal portion of YabP are shown. A putative ribosome-binding site of the yabP gene is doubly underlined. The experimentally determined transcription start site $(+1)$ and the deduced -10 and -35 regions are underlined. Consensus sequences recognized by $\mathrm{E} \sigma^{\mathrm{E}}$ are shown below.

Table 2. Sporulation frequencies in a strain carrying a yabQ deletion

Values in parentheses refer to percentage of spores.

\begin{tabular}{|lllll|}
\hline Strain & $\begin{array}{c}\text { Viable } \\
\text { cells } \mathbf{~ m}^{-1}\end{array}$ & $\begin{array}{c}\text { Heat-resistant } \\
\text { spores } \mathbf{~ m l}^{-1}\end{array}$ & $\begin{array}{c}\text { Lysozyme-resistant } \\
\text { spores } \mathbf{~ m}^{-1}\end{array}$ & $\begin{array}{c}\text { Chloroform-resistant } \\
\text { spores } \mathbf{~ m}^{-1}\end{array}$ \\
\hline 168 & $5 \cdot 6 \times 10^{8}$ & $3 \cdot 9 \times 10^{8}(69 \cdot 6)$ & $3 \cdot 7 \times 10^{8}(58 \cdot 9)$ & $4 \cdot 0 \times 10^{8}(71 \cdot 4)$ \\
ASK221 & $3 \cdot 1 \times 10^{8}$ & $3 \cdot 7 \times 10^{4}(0 \cdot 012)$ & $7 \cdot 4 \times 10^{6}(2 \cdot 4)$ & $1 \cdot 1 \times 10^{6}(0 \cdot 4)$ \\
\hline
\end{tabular}


The divIC gene is essential for cell division in vegetative growth and is required for asymmetric septation during sporulation (Sadaie \& Kada, 1983; Levin \& Losick, 1994). Consistent with this, additional transcripts covering divIC were detected, as schematically summarized in Fig. $1(\mathrm{a})$. Two transcripts, $5.3 \mathrm{~kb}$ (T1) and $3.7 \mathrm{~kb}$ (T2), were weak during vegetative growth, and a $1.0 \mathrm{~kb}$ transcript (T3) was detected during both vegetative and sporulation phases (Fig. 1b). Furthermore, a $0.5 \mathrm{~kb}$ transcript (T4) covering the yabR gene was strongly induced during the vegetative phase.

\section{Effects of inactivation of the $y a b P, y a b Q$ or $y a b R$ gene on spore formation}

Next, we examined the effects of inactivation of each of the three $y$ genes in the $y a b P-y a b R$ operon on sporulation. The insertion of exogenous plasmid DNA, pMUTINT3 (Vagner et al., 1998; Moriya et al., 1998), into the $y a b R$ gene by a single cross-over integration resulted in about a 10-fold reduction of sporulation frequency (data not shown); however, this was not further studied. Because inactivation of the yabP or yabQ gene by inserting the plasmid DNA leads to a polar effect on downstream divIC and yabR expression, we introduced an in-frame deletion within the yabP or yabQ gene by the two-step allele-replacement method (Asai et al., 2000). A promoter for divIC that is active from the vegetative phase (T3 in Fig. 1) was found within the $y a b Q$ gene by primer extension analysis (data not shown). Therefore, we avoided deleting the divIC promoter to obtain the yabQ deletion mutation. A strain carrying a deletion from codons 3 to 87 of the yabP structural gene (100 aa), ASK220, could sporulate and germinate, similar to the parental strain (data not shown). In contrast, a yabQ deletion mutant, ASK221, in which codons 4-140 of the structural gene (211 aa) were deleted, produced abnormal spores sensitive to lysozyme, chloroform and, especially, heat treatments (Table 2). Although transcription of the $y a b Q$ gene was weak during the vegetative phase in the wild-type cell (T1 and T2 in Fig. 1), growth of the yabQ mutant was comparable to that of the parental strain. Thus we postulated that the defective phenotype of the yabQ mutant in sporulation was due to the loss of the functional yabQ product at the phase of sporulation.

At the vegetative phase, $y a b Q$ is cotranscribed with $y a b M$, which is a paralogue of $s p o V B$, a gene required for maturation of the cortex (Popham \& Stragier, 1991). However, the inactivation of yabM did not affect the sporulation (data not shown).

\section{Synthesis of the spore cortex was blocked considerably in the yabQ mutant}

Normal spores become phase-bright under the phasecontrast microscope after spore coat synthesis followed by core dehydration (Piggot \& Coote, 1976; Errington, 1993). However, large amounts of spores produced in the yabQ mutant were phase-dark and did not become
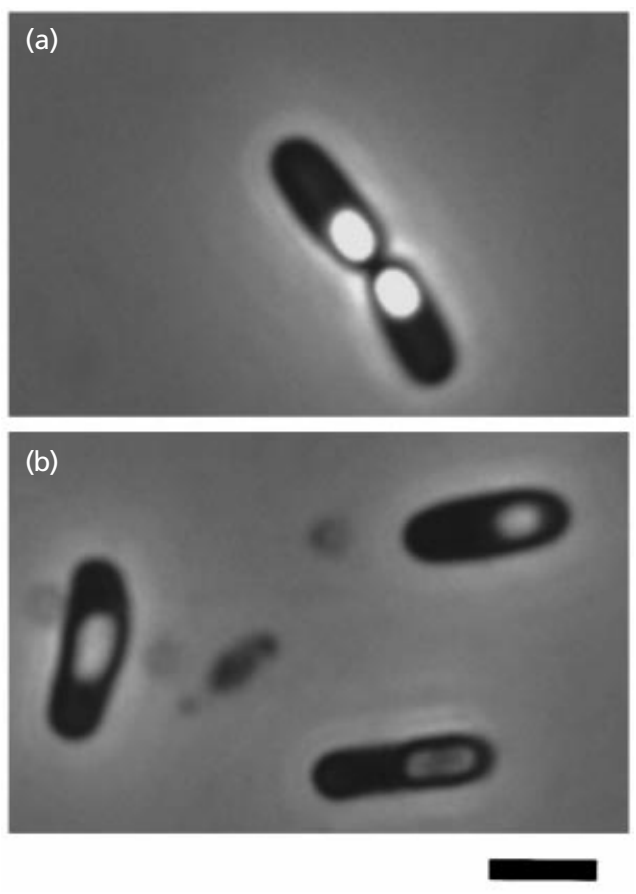

Fig. 3. Phase-contrast microscopy of sporulating cells of the wild-type 168 (a) and the yabQ mutant (b) in DS medium. Bar, $2 \mu \mathrm{m}$.

phase-bright, even after further incubation (Fig. 3). In wild-type cells, cortex synthesis was clearly observed under the electron microscope $8 \mathrm{~h}$ after the initiation of sporulation (Fig. $4 \mathrm{a}-\mathrm{d}$ ). In contrast, examination of the yabQ cells during sporulation revealed that synthesis of the spore cortex was blocked in them, resulting in production of defective sporangia that had almost entirely lost the spore cortex. In addition, the inner spore coat layer of the mutant spores seemed partially detached from the outer coat layer, suggesting that the YabQ deletion also affected the coat protein assembly (Fig. $4 \mathrm{e}-\mathrm{h}$ ). The spore cortex provides a heat-resistance property to the dormant spore. On the other hand, coat layers yield resistance to toxic solvents and lytic enzymes (Zheng et al., 1988; Naclerio et al., 1996; Takamatsu et al., 1999). Thus the characteristics of the morphology of the yabQ mutant spore were compatible with the sensitivity of the spore to lysozyme, chloroform and heat treatments.

\section{The YabQ protein localized on the surface of the forespore, independently of CotE and SpoIVA function}

The results described above indicated that YabQ protein is synthesized in the mother cell by $\mathrm{E} \sigma^{\mathrm{E}}$ and plays an important role in cortex and coat formation. To determine the precise role of YabQ in spore formation, we next examined localization. We introduced an inframe fusion of $g f p$ to yabQ into the B. subtilis chromosome and observed the sporulating cells under a 

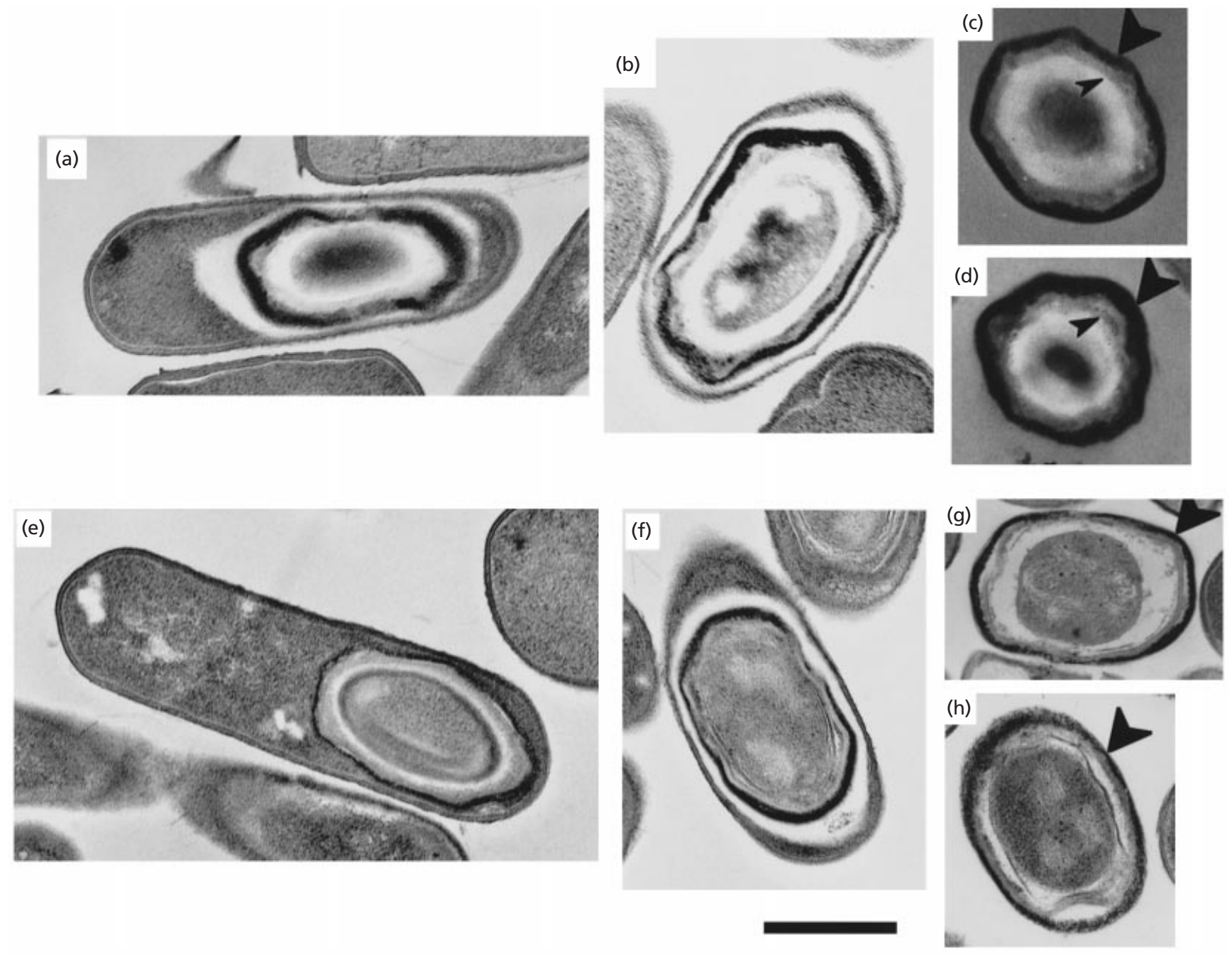

Fig. 4. Electron microscopy of spores of the wild-type $168(a, b, c$ and $d)$ and the yabQ mutant (e, $f, g$ and $h)$ strains. Samples were prepared from cells allowed to sporulate for $8(a, e), 10(b, f)$ and $18(c, d, g, h) h$ after the onset of sporulation. Small arrowheads indicate the boundary between the spore coat and the cortex. Large arrowheads indicate spore coat structure. Bar, $0.5 \mu \mathrm{m}$.

fluorescence microscope. Fluorescence in the vegetatively growing cell was nil. After expression of $y a b Q$ was initiated during sporulation, fluorescence appeared around the forespore (Fig. 5a, b), as observed for fluorescence from $g f p-s p o I V A$ (Fig. 5e). This observation indicated that the YabQ proteins were localized around the forespore. YabQ fluorescence was observed as an arch shape as well as a ring shape. We speculate that this difference was caused by asynchronous development of the sporulating cells under our conditions. A similar arch shape was observed for SpoVIA, while the SpoIVA proteins were thought to finally surround the forespore (Price \& Losick, 1999). Five putative transmembrane domains were predicted from the amino acid sequence of the YabQ protein by the Kyte-Doolittle plot (Kyte \& Doolittle, 1982), and a putative signal peptide sequence was found at the $\mathrm{N}$-terminus region, suggesting that it is a membrane protein (see information described in the website at http://bacillus. genome.ad.jp). Thus the localization of the YabQ-GFP fluorescence would suggest that the YabQ protein is associated with the forespore membrane.

CotE and SpoIVA proteins, the expression of which is also dependent on $\mathrm{E} \sigma^{\mathrm{E}}$, localize around the forespore and guide the proper assembly of spore coat proteins. The SpoIVA protein is also essential for cortex formation (Driks, 1999). We next examined the effects of their mutation on localization of the YabQ protein. The behaviour of the YabQ fluorescence was not affected by introducing the spoIVA or $\cot E$ mutation into the B. subtilis cells harbouring the yabQ-gfp fusion (Fig. 5c, d), supporting the assumption of localization of YabQ on the forespore membrane. Conversely, the fluorescence directed by spoIVA- and $\cot E-g f p$ fusion was not affected by the yabQ mutation (Fig. 5f, h). 

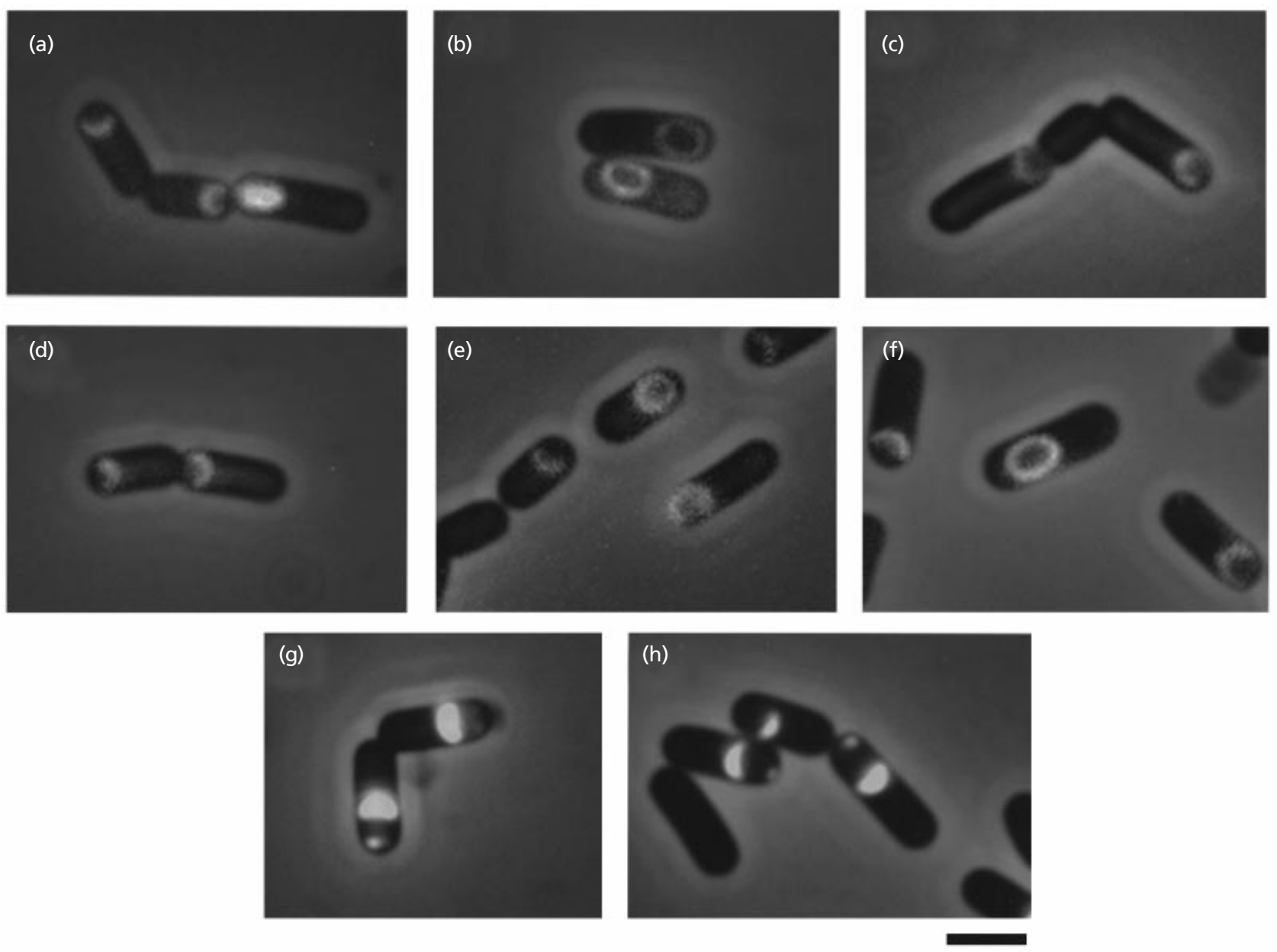

Fig. 5. Detection of YabQ-GFP, GFP-SpolVA and CotE-GFP fusions in sporulating B. subtilis cells. (a, b) Wild-type 168, (c) spoIVA178 or (d) cotE mutant carrying the yabQ-gfp fusion. (e) Wild-type 168 or (f) yabQ mutant carrying the gfp-spolVA fusion. (g) Wild-type or (h) yabQ mutant carrying the cotE-gfp fusion. Cells were allowed to sporulate in DS medium. Samples were withdrawn $6 \mathrm{~h}$ after the onset of sporulation. Phase-contrast and fluorescence microscope images were overlaid. Bar, $2 \mu \mathrm{m}$.

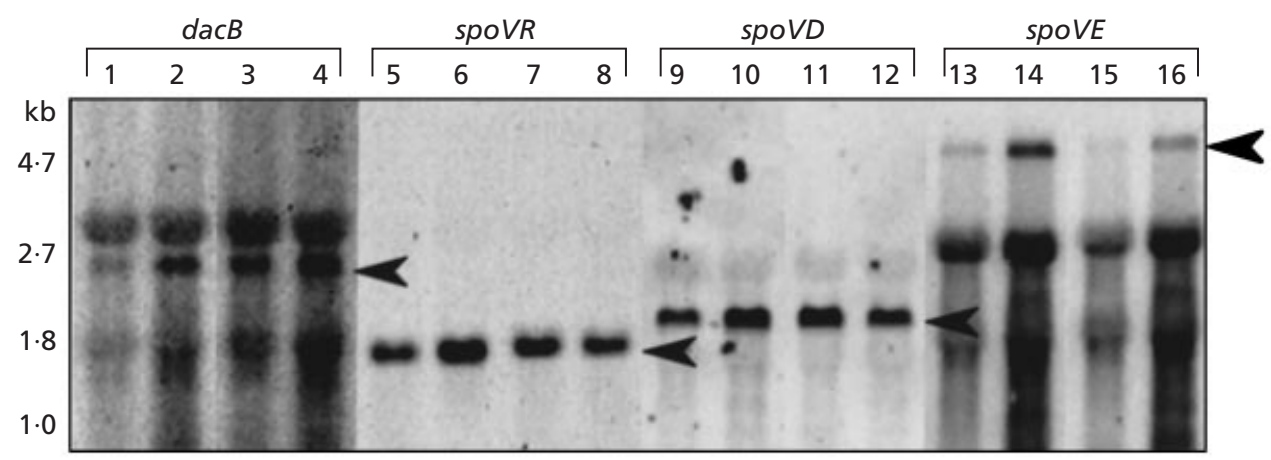

Fig. 6. Transcription of genes involved in cortex formation in the yabQ mutant. Northern hybridization was done to detect transcripts of dacB (lanes 1-4), spoVR (lanes 5-8), spoVD (lanes 9-12) and spoVE (lanes 13-16). The predicted transcripts of each gene are approximately $2 \cdot 5,1 \cdot 5,2.0$ and $4.9 \mathrm{~kb}$, respectively. Total RNA was prepared from cells of $B$. subtilis 168 (lanes 1, 2, 5, 6, 9, 10, 13 and 14) and the yabQ mutant (lanes 3, 4, 7, 8, 11, 12, 15 and 16), which were harvested at 4 (lanes 1, 3, 5, 7, 9, 11, 13 and 15) and 6 (lanes 2, 4, 6, 8, 10, 12, 14 and 16) h after the end of vegetative growth. Arrowheads represent the positions of transcripts. 


\section{Effect of the yabQ deletion on the expression of genes involved in cortex synthesis}

We also asked if the YabQ protein might regulate the expression of genes involved in spore cortex synthesis. Several $\mathrm{E} \sigma^{\mathrm{E}}$-dependent genes, mostly designated spoV, have been reported to participate in cortex synthesis. A family of so-called penicillin-binding proteins (PBPs) catalyses development of the peptidoglycan layer of the cortex (DacB and SpoVD) (Daniel et al., 1994; Popham et al., 1999). SpoVE protein, which is highly homologous with cell elongation protein (RodA), is also required for synthesis of the cortex peptidoglycan (Daniel \& Errington, 1993; Henriques et al., 1998). Mutation in the spoVR gene causes a defect in cortex synthesis, although the precise function was not obvious (Beall \& Moran, 1994). Northern analysis of the expression of the $d a c B$, spoVD, spoVE and spoVR genes in the yabQ mutant revealed that they were normally expressed and were independent of YabQ function (Fig. 6).

When lacZ was fused to spoIID (Rong et al., 1986), sspE (Sun et al., 1989) and $\operatorname{cotA}$ (Zheng \& Losick, 1990) (kindly provided by Dr P. Stragier, Institut de Biologie Physico-Chimique, Paris, France), transcribed by $\mathrm{E} \sigma^{\mathrm{E}}$, $\mathrm{E} \sigma^{\mathrm{G}}$ and $\mathrm{E} \sigma^{\mathrm{K}}$, respectively, and introduced into the $a m y E$ locus on the chromosome of the $y a b Q$ mutant, expression of the fusions was similar to that seen in the wild-type strain, suggesting that those sporulation sigma factors were normally activated in the yabQ mutant (data not shown).

\section{Role of the YabQ protein in spore formation}

Extensive Northern analysis revealed $\mathrm{E} \sigma^{\mathrm{E}}$-dependent transcription from the yabP-yabQ-divIC-yabR operon during sporulation. Deletion of the first ORF, the yabP gene, had no apparent effect on either sporulation or germination. However, deletion of the second ORF, yabQ, made spores sensitive to lysozyme, chloroform and, especially, heat treatment. Microscopic analysis showed that $y a b Q$ mutant spores possessed no obvious spore cortex layer and had an impaired spore coat, suggesting that $y a b Q$ plays an important role in synthesis of the spore cortex and coat. The YabQ protein was predicted to have five transmembrane domains and a signal sequence at the $\mathrm{N}$-terminus region. YabQ fluorescence signals were observed surrounding the forespore independently of CotE and SpoVIA functions, suggesting that YabQ is associated with the forespore membrane. Expression of the genes participating in cortex synthesis and the sporulation sigma factors $\sigma^{\mathrm{E}}, \sigma^{\mathrm{G}}$ and $\sigma^{\mathrm{K}}$ occurred normally in the yabQ deletion mutant. These findings suggest that the YabQ protein plays a direct role in cortex formation. An interesting possibility might be that YabQ is a transporter for components required for synthesis of the spore cortex and the defect affects coat assembly.

During preparation of this manuscript, Fawcett et al. (2000) reported analysis of genes expressed during sporulation by transcriptional profile analysis with a macro-array. They began building null mutations of possible sporulation genes thus identified, and deletion of $y a b P$ or $y a b Q$ was found to block sporulation at a late stage.

\section{ACKNOWLEDGEMENTS}

We thank colleagues in our laboratory for valuable discussions and M. Ohara for language assistance. We thank K. D. Price and R. Losick for strain KP429. This work was supported by a grant, JSPS-RFTF96L00105, from the Japan Society for the Promotion of Science and a Grant-in-Aid for Scientific Research on Priority Areas (C) from The Ministry of Education, Science, Sports, and Culture Japan.

\section{REFERENCES}

Asai, K., Baik, S. H., Kasahara, Y., Moriya, S. \& Ogasawara, N. (2000). Regulation of the transport system for $\mathrm{C}_{4}$-dicarboxylic acids in Bacillus subtilis. Microbiology 146, 263-271.

Beall, B. \& Moran, C. P., Jr (1994). Cloning and characterization of spoVR, a gene from Bacillus subtilis involved in spore cortex formation. J Bacteriol 176, 2003-2012.

Coot, J. G. (1972). Sporulation in Bacillus subtilis. Characterization of oligosporogenous mutants and comparison of their phenotypes with those of asporogenous mutants. J Gen Microbiol 71, 1-15.

Daniel, R. A. \& Errington, J. (1993). DNA sequence of the murEmurD region of Bacillus subtilis 168. J Gen Microbiol 139, 361-370.

Daniel, R. A., Drake, S., Buchanan, C. E., Scholle, R. \& Errington, J. (1994). The Bacillus subtilis spoVD gene encodes a mother-cellspecific penicillin-binding protein required for spore morphogenesis. J Mol Biol 235, 209-220.

Driks, A. (1999). Bacillus subtilis spore coat. Microbiol Mol Biol Rev 63, 1-20.

Errington, J. (1993). Bacillus subtilis sporulation: regulation of gene expression and control of morphogenesis. Microbiol Rev 57, $1-33$.

Fawcett, P., Eichenberger, P., Losick, R. \& Youngman, P. (2000). The transcriptional profile of early to middle sporulation in Bacillus subtilis. Proc Natl Acad Sci U S A 97, 8063-8068.

Henriques, A. O., Glaser, P., Piggot, P. J. \& Moran, C. P., Jr (1998). Control of cell shape and elongation by the $\operatorname{rodA}$ gene in Bacillus subtilis. Mol Microbiol 28, 235-247.

Igo, M. M. \& Losick, R. (1986). Regulation of a promoter that is utilized by minor forms of RNA polymerase holoenzyme in Bacillus subtilis. J Mol Biol 191, 615-624.

Kawamura, F., Saito, H. \& Ikeda, Y. (1980). Bacteriophage $\phi 1$ as a gene-cloning vector in Bacillus subtilis. Mol Gen Genet 180, 259-266.

Kodama, T., Takamatsu, H., Asai, K., Kobayashi, K., Ogasawara, N. \& Watabe, K. (1999). The Bacillus subtilis yaaH gene is transcribed by SigE RNA polymerase during sporulation, and its product is involved in germination of spores. J Bacteriol 181, 4584-4591.

Kyte, J. \& Doolittle, R. F. (1982). A simple method for displaying the hydropathic character of a protein. J Mol Biol 157, 105-132.

Levin, P. A. \& Losick, R. (1994). Characterization of a cell division gene from Bacillus subtilis that is required for vegetative and sporulation septum formation. J Bacteriol 176, 1451-1459.

Losick, R., Youngman, P. \& Piggot, P. J. (1986). Genetics of endospore formation in Bacillus subtilis. Annu Rev Genet 20, 625-669. 
Moriya, S., Tsujikawa, E., Hassan, A. K., Asai, K., Kodama, T. \& Ogasawara, N. (1998). A Bacillus subtilis gene-encoding protein homologous to eukaryotic SMC motor protein is necessary for chromosome partition. Mol Microbiol 29, 179-187.

Naclerio, G., Baccigalupi, L., Zilhao, R., De Felice, M. \& Ricca, E. (1996). Bacillus subtilis spore coat assembly requires $\cot H$ gene expression. J Bacteriol 178, 4375-4380.

Nicholson, W. L. \& Setlow, P. (1990). Sporulation, germination and outgrowth. In Molecular Biological Methods for Bacillus, pp. 391-450. Edited by C. R. Harwood \& S. M. Cutting. Chichester: Wiley.

Ogasawara, N., Nakai, S. \& Yoshikawa, H. (1994). Systematic sequencing of the 180 kilobase region of the Bacillus subtilis chromosome containing the replication origin. DNA Res 1, 1-14.

Piggot, P. J. \& Coote, J. G. (1976). Genetic aspects of bacterial endospore formation. Bacteriol Rev 40, 908-962.

Popham, D. L. \& Stragier, P. (1991). Cloning, characterization, and expression of the spoVB gene of Bacillus subtilis. J Bacteriol 173, 7942-7949.

Popham, D. L., Gilmore, M. E. \& Setlow, P. (1999). Roles of lowmolecular-weight penicillin-binding proteins in Bacillus subtilis spore peptidoglycan synthesis and spore properties. J Bacteriol 181, 126-132.

Price, K. D. \& Losick, R. (1999). A four-dimensional view of assembly of a morphogenetic protein during sporulation in Bacillus subtilis. J Bacteriol 181, 781-790.

Reynolds, E. S. (1963). The use of lead citrate at high $\mathrm{pH}$ as an electron-opaque stain in electron microscopy. J Cell Biol 17, 208-212.

Rong, S., Rosenkrantz, M. S. \& Sonenshein, A. L. (1986). Transcriptional control of the Bacillus subtilis spoIID gene. J Bacteriol 165, 771-779.

Sadaie, Y. \& Kada, T. (1983). Effect of septum-initiation mutation on sporulation and competent cell formation in Bacillus subtilis. Mol Gen Genet 190, 176-178.
Schaeffer, P., Millet, J. \& Aubert, J.-P. (1965). Catabolite repression of bacterial sporulation. Proc Natl Acad Sci U S A 54, 704-711.

Spurr, A. R. (1969). A low-viscosity epoxy resin embedding medium for electron microscopy. J Ultrastruct Res 26, 31-43.

Stragier, P. \& Losick, R. (1996). Molecular genetics of sporulation in Bacillus subtilis. Annu Rev Genet 30, 297-341.

Stragier, P., Bonamy, C. \& Karmazyn-Campelli, C. (1988). Processing of a sporulation sigma factor in Bacillus subtilis: how morphological structure could control gene expression. Cell 52, 697-704.

Sun, D. X., Stragier, P. \& Setlow, P. (1989). Identification of a new sigma-factor involved in compartmentalized gene expression during sporulation of Bacillus subtilis. Genes Dev 3, 141-149.

Takamatsu, H., Kodama, T., Nakayama, T. \& Watabe, K. (1999). Characterization of the $y \mathrm{rbA}$ gene of Bacillus subtilis involved in resistance and germination of spores. J Bacteriol 181, 4986-4994.

Takamatsu, H., Kodama, T., Imamura, A., Asai, K., Kobayashi, K., Nakayama, T., Ogasawara, N. \& Watabe, K. (2000). The Bacillus subtilis yabG gene is transcribed by SigK RNA polymerase during sporulation, and $y a b G$ mutant spores have altered coat protein composition. J Bacteriol 182, 1883-1888.

Vagner, V., Dervyn, E. \& Ehrlich, S. D. (1998). A vector for systematic gene inactivation in Bacillus subtilis. Microbiology 144, 3097-3104.

Zheng, L. B. \& Losick, R. (1990). Cascade regulation of spore coat gene expression in Bacillus subtilis. J Mol Biol 212, 645-660.

Zheng, L. B., Donovan, W. P., Fitz-James, P. C. \& Losick, R. (1988). Gene encoding a morphogenic protein required in the assembly of the outer coat of the Bacillus subtilis endospore. Genes Dev 2, 1047-1054.

Received 17 August 2000; revised 30 November 2000; accepted 13 December 2000. 